rollo internacional/Venezuela

\title{
Niños investigadores
}

\section{Introducción. Esta experiencia educativa es desarrollada por una maestra} de segundo grado de Educación Básica de la Unidad Educativa 'La Mata', Municipio Cabudare, Estado Lara, Venezuela. Dicha institución no ha tenido inje-

María Herrera

Zuleima Galíndez

Fecha de ctalsoración: enem 15 de 2002

Fecla de aceptación: 25 de septiembre de 2003

Resumen. El propósito de este proyecto es motivar a los niños a construir proyectos a partir de sus intereses y validarlos entre ellos. Cada uno elige su tema de interés e inicia un proceso de indagación, búsqueda, experimentación y validación de su propuesta. Los niños incursionan de esta manera en el proceso de investigación que les permite ser protagonistas de su aprendizaje y reconocer que el conocimiento es una construcción colectiva.

Palabras clave: Investigación, aprendizaje, experimentar, proceso, habilidades, enseñanza, innovación, constructivismo

Summary. The purpose of this project is to motivate the children to build projects starting from their interests and validate them among them. Each one chooses their topic of interest and begins an inquiry process, search, experimentation and validation of its proposal. By this way, the children incure in the investigation process that allows them to be main characters of their learning and to recognize that knowledge is a join construction.

Key words: Investigation, learning, to experience, process, abilities, education, innovation, constructivism. rencia directa en la experiencia, ya que sólo participaron de la misma algunos miembros de la escuela después de ver los primeros resultados. La experiencia se desarrolla a partir del año escolar 1999-2000, al ejecutar el tercer Proyecto Pe. dagógico de Aula, en un grupo de 32 niños de 2 do grado. Para entonces se tenía información del diagnóstico inicial de los estudiantes, representantes y docente.

La mayor preocupación de la maestra era lograr que los niños se involucraran en el proceso de enseñan. za-aprendizaje de manera que la clase no resultara tediosa, repetitiva ni traumática para ellos, sino que hubiese un ambiente de aprendizaje enriquecedor, innovador $y$, sobre todo, que los niños se sintiesen libres, felices de trabajar en el aula y fuera de ella de manera natural.

En este periodo de tiempo, la escuela fue visitada por el Bus de la Ruta de la Ciencia - proyecto del Pedagógico de Barquisimeto para incentivar a los estudiantes a la investigación-, pero sólo para los estudiantes de la 2da. Etapa. La maestra habló de ese proyecto a los niños y a sus representantes, y entre todos buscaron la manera de que los tomaran en cuenta. Por ello decidieron elaborar el proyecto: Niños investigadores, a través de experimentos sencillos y novedosos.

La maestra pretendía:

a. Propiciar actividades investigativas a fin de inducir a los estudiantes a razonar y a comparar aspectos de la vida natural. 
b. Experimentar situaciones de aprendizaje innovadoras donde se evidenciara la importancia de salir del salón de clase para la construir aprendizaje significativo.

Por otra parte, consideró relevante dar a conocer la experiencia realizada:

a Porque el docente es mediador del proceso enseñanza-aprendizaje.

b. Los niños y sus representantes son los verdaderos protagonistas.

c. La innovación dentro y fuera del aula despierta el interés de los estudiantes por el aprendizaje.

d. El aprendizaje no se construye sólo dentro de cuatro paredes.

e. La motivación es determinante en cualquier proceso.

f. La imaginación y la creatividad están presentes en nosotros.

Las actividades realizadas conllevaron a la ejecución de maravillosos experimentos que los niños mostraron con recursos elaborados por ellos mismos, de manera sencilla, con explicaciones claras, fluidez verbal, y con mucha seguridad. En ello se observó que cuando se trabaja en lo realmente interesante y novedoso para los estudiantes, éstos se consideran dueños de su aprendizaje, por tanto los resultados son excelentes.

\section{Referentes teóricos}

Concepción constructivista del aprendizaje

Esta concepción subraya la importancia del proceso constructivo del conocimiento y relativiza el papel de las estrategias educativas para obtener dicho conocimiento (Hernández, 1997). De ello se deduce que es el alumno quien construye sus propios aprendizajes, pero eso sólo es posible con la intervención de otra persona que actúa como mediador; es decir, las ayu- das que proporciona el docente $\mathrm{u}$ otras personas, como pueden ser sus compañeros.

Luque Lozano y otros (1997), plantean que los docentes que adoptan una postura constructivista del aprendizaje y la enseñanza, contribuyen a solucionar los problemas en el aula, utilizando los recursos que le ofrece el medio, por lo que comprenden y enfrentan situaciones difíciles que se presentan en las escuelas.

En la enseñanza-aprendizaje, como proceso interactivo en el aula, intervienen docente-estudiante, estudiantedocente; por tanto, para que el alumno aprenda, no depende solamente de él, sino del grado en que las ayudas del profesor estén ajustadas al nivel del alumno en cada tarea de aprendizaje. Si el ajuste es apropiado, el alumno aprenderá y progresará, cualquiera que sea su nivel actual. Pero si no se produce la adaptación entre lo que el alumno es capaz de hacer y las ayudas que le ofrece el maestro a través de sus estrategias de enseñanza, no aprenderá. En este sentido, la función del docente es hacer lo que esté a su alcance para promover el máximo progreso posible en los alumnos para que aprendan.

Por eso, se necesitan estrategias adecuadas para dar respuesta a la necesidad de aprendizaje de cada alumno y del grupo. Conjugar tales estrategias, equivale a realizar ajustes a los Proyectos de Aula. Sin embargo, la clave para esto es un docente reflexivo que entiende su actividad profesional, que asuma la enseñanza como una tarea compleja para la que no existen respuestas 'prefabricadas'. Para facilitar el aprendizaje de cualquier alumno, se precisa de una actitud de indagación, de búsqueda, de experimentación, que permita ver y sentir estos problemas, esta complejidad e incertidumbre, como un desafío profesional, no como un obstáculo penoso, por ello el docente promover tales actitudes a sus estudiantes.

\section{El método de investigación}

Bethencourt (1997) sugiere, para la elaboración de los Proyectos de Aula, después de realizar el diagnóstico inicial, que la elección de un método en particular de- 
penderá de las intenciones educativas de un momento dado; sin embargo, resalta que el método de investigación es uno de los más completos, porque además de desarrollar habilidades investigativas en los estudiantes, estimula el aprendizaje cognoscitivo y actitudinal. En este método, el contenido conceptual de aprendizaje se establece en función de la comprensión y de la elaboración de definiciones personales de la temática estudiada. Tal comprensión se produce mediante actividades investigativas que inducen al estudiante a razonar, comparar, concluir y confrontar. Asimismo, los contenidos procedimentales se desarrollan al crear o al construir un objeto; mientras que los actitudinales se desarrollan al considerar que no sólo el conocimiento adquirido es útil, sino que hay que apreciar lo realizado por otros, colaborar, solidarizarse.

\section{Desarrollo de la experiencia}

La experiencia Niños investigadores se desarrolló en cuatro fases, y tuvo una duración de cuatro semanas, así:

\section{Primera fase}

El diagnóstico se realizó a través de la técnica de lluvias ideas y los datos se registraron en pápelografos, los cuales se colocaron en las paredes del aula de clase. En este registro cualitativo se elaboraron tres categorías: lo que los niños querían hacer, sus inquietudes, sus intereses. Allí se detectó lo que los niños querían saber sobre la Ruta de la Ciencia. Por ello se les presentó, además de alimentos, recursos naturales como plantas; también se realizaron vivencias sobre el aire y la respiración, lo cual permitió determinar los conocimientos previos de los estudiantes. Las respuestas dadas eran de este orden: 'todas las hojas son verdes', 'el aire no pesa', 'las plantas no respiran', 'las plantan necesitan agua'. De manera que se orientó la discusión entre ellos para darle un nombre al proyecto, por lo cual se denominó: Niños investigadores.

\section{Segunda fase}

Se reunieron los representantes con la docente para buscar la manera de aplicar lo aprendido en el Bus de la ruta de la ciencia. Se propuso trabajar con pequeños experimentos de ciencias que resultaran atractivos para los niños, quienes tendrían que investigar y realizar experimentos que luego serían demostrados. Se buscó información acerca de experimentos sencillos que satisficieran las inquietudes demostradas, previa conversación con el grupo. Luego se formaron cinco grupos de trabajo con tres representantes como coordinadores de equipo.

Tercera fase

Se realizaron las demostraciones y las exposiciones en cuatro jornadas de trabajo con la asistencia de los demás representantes - los que no eran coordinadores- y una docente de 2do grado. Los niños hicieron las demostraciones con recursos traídos de sus casas:

- Para resolver la pregunta, zpor qué el color verde de las hojas?, introdujeron hojas de plantas en dos recipientes; uno con alcohol, otro con agua. En primero, el líquido se puso verde.

- ¿Por qué el aire pesa? Los niños realizaron una balanza con los palitos de un gancho de ropa y tapas de leche. En cada una de las tapas colocaron dos globos inflados, luego desinflaron uno y demostraron que el aire pesa.

- ¿Cuáles alimentos contienen almidón? Para este experimento, los niños utilizaron papa, yuca, aguacate y cambur ${ }^{1}$. A cada uno de ellos le pusieron tres gotas de limón. Los dos primeros se pusieron rojizos, demostrando que tienen almidón, los otros no.

- ¿Por qué las plantas respiran? Los niños colocaron plantas en un recipiente con tapa y otro sin tapa. Días después la planta que estaba tapada muere, la otra no.

- ¿Cómo se trasmite el sonido a través de los líquidos? Los estudiantes utilizaron dos piedras y un recipiente con agua. Golpearon las piedras unas

1 Plátano. 
contra otras fuera del recipiente, luego las introdujeron, detectando que en el agua el sonido es más intenso.

- ¿Por qué las plantas necesitan alimentarse? Los niños utilizaron una flor blanca, un vaso con agua y colorante vegetal. Dejan la flor en el vaso y al otro día observan que ésta adquiere el tono del colorante.

- ¿Qué necesitan las plantas para crecer? En un envase con periódico, los niños ponen caraotas, y en otro con arena, granos de maíz. Ubican ambos envases en un sitio de manera que reciban luz solar y todos los días los riegan con agua. En cierto tiempo observan cómo crecen las plantitas. Con ello demostraron que las plantas necesitan luz y agua para vivir.

\section{Cuarta fase}

Se reconoció el trabajo realizando una visita al museo de la Ciencia de los Padres Jeverianos en la ciudad de Barquisimeto. Igualmente, hicimos una convivencia con los representantes de los alumnos.

Por último, la evaluación, se registró atendiendo a los criterios exigidos para este nivel en relación con dos categorías: el logro o no de las competencias. Para ello, además de considerar hábitos de trabajo, organización y presentación del experimento, se consideró si preguntas como: ¿por qué el color verde de las hojas?, ¿por qué el aire pesa?, etc., fueron respondidas satisfactoriamente por los niños.

Otro logro - considerado por la maestra como el más importante-, fue la alegría de los niños al sentir que estaban aprendiendo de manera espontánea; es decir, ellos buscaban su información.

Asimismo, el desarrollo de las habilidades en la realización de las investigaciones sencillas, les permitió adquirir mejores niveles de: respeto, convivencia, igualdad, responsabilidad, solidaridad, tolerancia, esperanza, ilusión, libertad, honestidad, perseverancia y cooperación.

\section{Resultados}

Este trabajo demostró que en un ambiente de libertad; compañerismo, unión y, sobre todo, gracias al apoyo de los representantes dentro del aula, se pueden obtener resultados óptimos en el proceso de enseñanza-aprendizaje. Los niños se perciben seguros, felices, y se detecta en ellos el espíritu de indagar hasta llegar por sí mismos a elaborar sus conclusiones, haciéndose partícipes directos de su aprendizaje. Entre los efectos positivos de la experiencia se señalan:

- Los niños asumen el trabajo escolar con responsabilidad.

- Los niños se sienten libres al ejecutar el trabajo escolar.

- Se fomenta el trabajo en grupo.

- Los niños se apropian de su aprendizaje.

- Los representantes se hacen y se sienten protagonistas directos del aprendizaje de los niños.

- Se desarrollan y enriquecen habilidades que facilitan el desempeño escolar.

- Se creó un comité de madres voluntarias dentro del proceso de enseñanza-aprendizaje.

- Se aprende a través de la observación directa.

- La experiencia sirvió para despertar el interés de otros docentes tanto de la institución como otras instituciones escolares, así como para integrar a padres y representantes al trabajo en el aula.

- Se afianzaron las interrelaciones grupales.

Entre las dificultades se encuentran la timidez y la inseguridad de algunos niños, lo cual se enfrentó sugiriendo a los niños hacer grupo con un amigo o compañero de más confianza, y exponer su planteamiento al grupo. 
Asimismo, la experiencia sirvió para hacer modificaciones en los años siguientes como: a. Integrar a los representantes desde el inicio del año escolar. b. Utilizar espacios de la Institución como el patio, el aulataller y los parques para hacer un aprendizaje efectivo. c. Compartir, en los círculos de acción docente, las experiencias realizadas para motivar a los colegas a realizar tales prácticas. $\mathbf{m}$

\section{Referencias}

BETHENCOURT, M. Del proyecto educativo a la planificación en el aula. Movimiento Pedagóǵgico. Dossier V, $\mathrm{N}^{0}$ 15. Venezuela, 1997.

HERNÁNDEZ, A. 'Las visiones del constructivismo'. En: La construcción del conocimiento escolar. Rodrigo, $M$. y Arnay, J. España: Paidós, 1997.

LUQUE LOZANO, A; Ortega, R; Cubero, $R$. Concepciones constructivistas y Práctica Escolar. En: La construcción del conocimiento escolar. Rodrigo, M. y Arnay, J. España: Paidós, 1997.

\section{Diálogo del conocimiento}

Alegria. É o que se sente ao ler o trabalho desta professora venezuelana. Quase se pode ver a alegria dos alunos investigando sobre os assuntos escolhidos, estimulados depois de terem uma vivência em um espaço especial sobre a ciéncia no Bus de la Ruta de la Ciencia. Nāo é difícil imaginar o brilho nos seus olhos. Sim, porque brilham os olhos de todo aquele que se sente desafiado frente a algo desconhecido.

Năo hă alegria maior que aprender... A alegria dos pais e das mães ('los representantes') também se pode imaginar. Um ambiente de liberdade, união e companheirismo somado a presença deles certamente $f$ uma garantia de um ensino com ótimos resultados. Mas o que dizer da alegria da professora Zuleima? A sua alegria nāo deve ser menor.

Qualquer profissional se sentiria assim ao perceber que a sua motivaçăo pelo trabalho se transfere para o trabalho dos seus alunos. Mas não se trata de uma motivação passageira, efemera. Tal como o alegria do Carnaval...

Por envolver planejamento, sustentaçāo teórica consistente e controle do desenvolvimento das situaçōes de aprendizagem que vão sendo propostas, este entusiasmo resulta em mais conhecimento sobre as situaçōes vividas. Ela já sabe como fazer ainda melhor na próxima vez.

Da mesma forma, as seus alunos também já sabem que agora podem fazer outras indagaçōes. E mais, se estas perguntas puderem ser feitas em grupo, se tratarem de coisas relevantes para sua vida e se puderem ser testadas livremente, as respostas encontradas poderăo ajudar a uma emancipaçăo no seu entorno: nem a busca do seu domínio e nem a da sua submissto.

Enfim, o interesse leva ao conhecimento que traz mais interesse, que por sua vez resulta em mais conhecimento e assim por adiante.... E nos, enredados nesta malha iberoamericana de professores que fazem investigaço desde a sua escola, o que sentimos? Mais alegria ainda, pois vamos percebendo que nossos sonhos se juntam a outros sonhos formando os 'nodos' firmes desta rede.

Se reforça a ideia central que nos guia de que o conhecimento nâo está nunca acabado: nem o nosso conhecimento profissional, nem o conhecimento dos alunos, nem o conhecimento escolar, etc.

E eu? Estou agradecido por poder expressar a alegria de ler o trabalho da Zuleima e por poder conhecer melhor a minha realidade ao conhecer a realidade dela e assim podermos nos identificar na diferença e nos encontrar na distància.

Joäs Batista Siqueirs Hasses 